
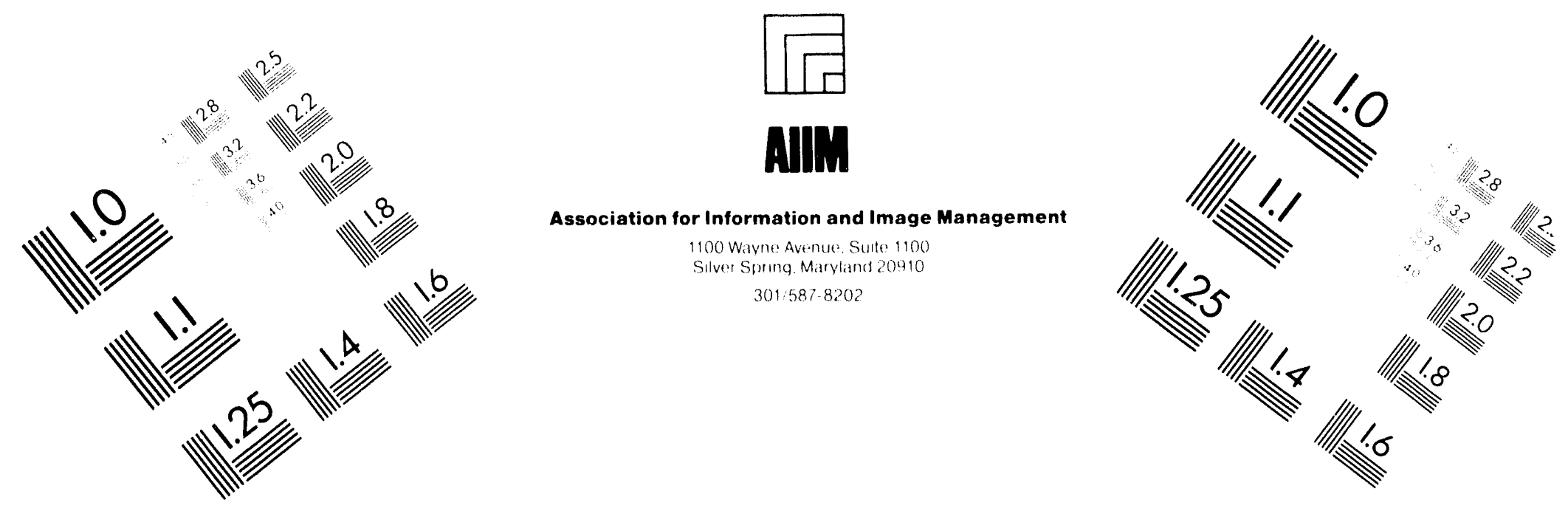

\title{
Centimeter
}

10 Inches
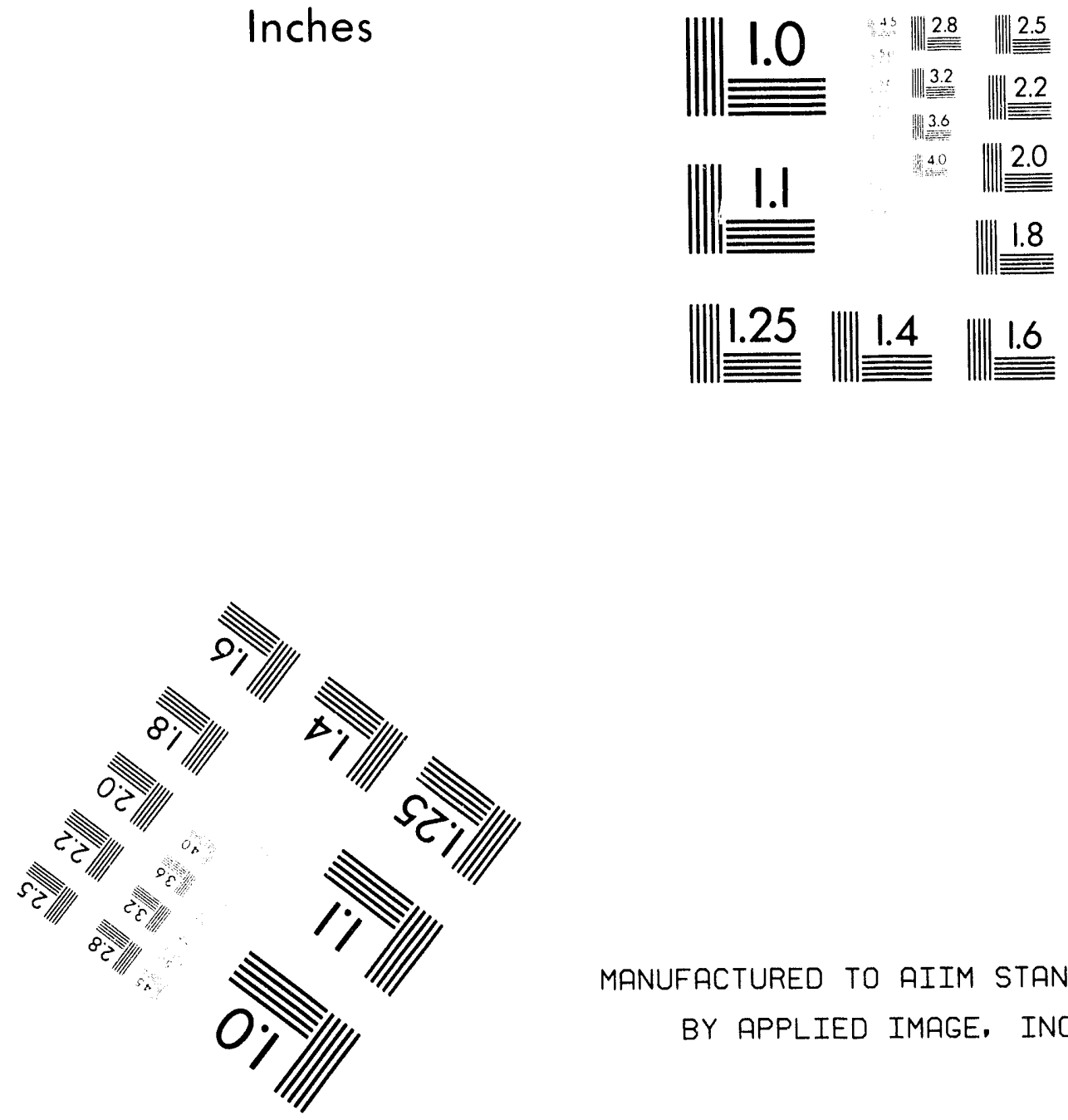

MANUFACTURED TO AIIM STANDARDS

BY APPLIED IMAGE. INC.

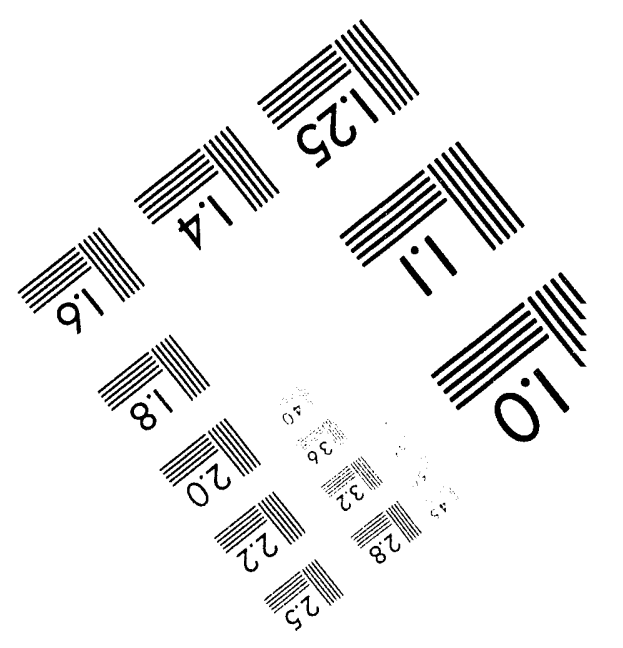



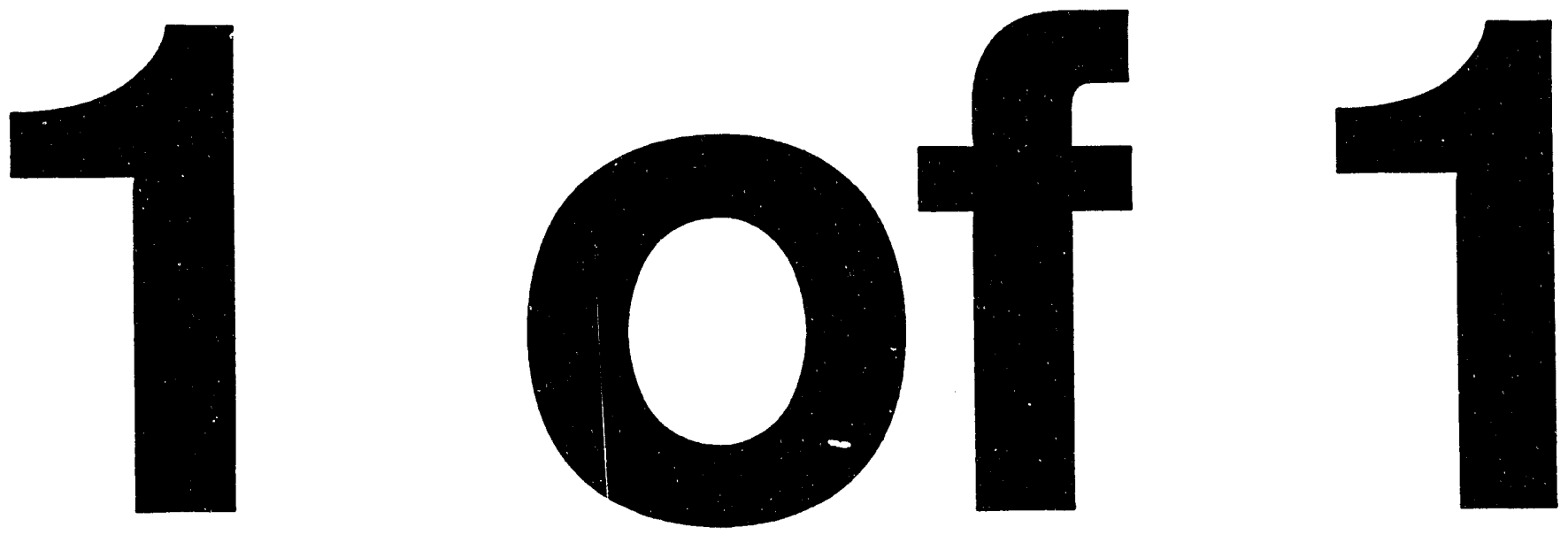
BNL- 60440

Informal Report

Limited Distribution

SNS-6

\section{RING ENERGY AND CURRENT CONSIDERATIONS FOR SPALLATION NEUTRON SOURCE*}

L.N. Blumberg

April 1994

NSLS Department

BROOKHA VEN NATIONAL LABORATORY

Upton, New York 11973

*This work was performed under the auspices of the U.S. Department of Energy.

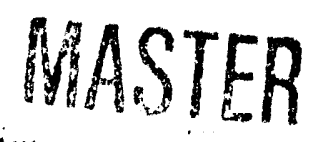

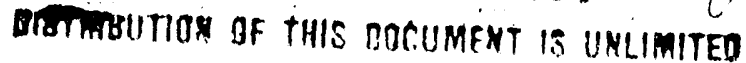

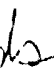




\section{Introduction}

The most desirable energy $\mathrm{E}_{\mathrm{o}}$ of protons from the synchrotron and thus beam current $\bar{I}$ to produce a given beam power $P_{B}$ involves a balanced consideration of neutron production capability, accelerator beam stability, user requirements, and cost considerations. These issues are sufficiently complex such that a precise optimization is probably unobtainable and has, to the best of our present knowledge, not been fully addressed in the literature. All of the existing spallation neutron sources except ISIS have been designed with pre-existing constraints or purposes and their parameters are summarized, where known, in Table I. Proposed dedicated spallation sources and tentative parameters, when known, are given in Table II. Bauer ${ }^{17}$ has discussed the questions of beam energy, beam current, pulse width, and repetition rate for the next generation of dedicated sources and his conclusions are incorporated in the present report.

TABLE I. Parameters of Existing SNS Facilities

\begin{tabular}{|c|c|c|c|c|c|c|c|c|}
\hline Ring & Location & $\begin{array}{l}\text { Einj } \\
(\mathrm{MeV})\end{array}$ & $\begin{array}{l}\text { Eout } \\
(\mathrm{GeV})\end{array}$ & $\begin{array}{l}\mathrm{Rp} \\
\text { (pps) }\end{array}$ & $\begin{array}{l}\mathrm{C} \\
(\mathrm{m})\end{array}$ & $\begin{array}{l}\Delta \mathrm{t} \\
(\mu \mathrm{s})\end{array}$ & $\begin{array}{l}I \\
(\mu \mathrm{A})\end{array}$ & $\begin{array}{l}\mathrm{A} / \pi \\
(\mathrm{mm}-\mathrm{mr})\end{array}$ \\
\hline IPNS $^{1}$ & ANL, Argonne & 50 & 0.5 & 30 & & 0.1 & 13 & 500 \\
\hline ISIS $^{2}$ & RAL, U.K. & 70 & 0.8 & 50 & 163.4 & 0.45 & 200 & \\
\hline KENS $^{3}$ & KEK, Japan & 40 & 0.5 & 20 & & 0.05 & 5 & \\
\hline $\mathrm{MPNS}^{4}$ & Moscow, Russia & 160 & & & & & 20 & \\
\hline PSR $^{5}$ & $\begin{array}{l}\text { LANSCE } \\
\text { Los Alamos }\end{array}$ & 800 & 0.8 & 20 & & 0.27 & 75 & \\
\hline${ }^{*} \operatorname{SIN}^{6}$ & PSI, Switz. & -- & 0.59 & cont. & & -- & 1000 & \\
\hline
\end{tabular}

TABLE II. Parameters of Proposed Dedicated SNS Facilities

\begin{tabular}{|c|c|c|c|c|c|c|c|c|}
\hline Ring & Location & $\begin{array}{l}\text { Einj } \\
(\mathrm{MeV})\end{array}$ & $\begin{array}{l}\text { Eout } \\
(\mathrm{GeV})\end{array}$ & $\begin{array}{l}\text { Rp } \\
\text { (pps) }\end{array}$ & $\begin{array}{l}C \\
(\mathrm{~m})\end{array}$ & $\begin{array}{l}\Delta \mathrm{t} \\
(\mu \mathrm{s})\end{array}$ & $\begin{array}{l}I \\
(\mathrm{~mA})\end{array}$ & $\begin{array}{l}\mathrm{A} / \pi \\
(\mathrm{mm}-\mathrm{mr})\end{array}$ \\
\hline ANS' & Moscow, Russia & 1000 & 10 & 40 & 573 & 2 & 0.4 & \\
\hline AUSTRON ${ }^{8}$ & Austria & $70-130$ & 1.66 & $25-50$ & 202 & $<1$ & 0.1 & 150 \\
\hline \multirow[t]{2}{*}{ ESS $^{9}$} & RAL/Wuppertal & $\begin{array}{l}800 \\
1200 \\
2400\end{array}$ & $\begin{array}{l}3 @ 0.8 \\
2 @ 1.2 \\
1 @ 2.4\end{array}$ & $\begin{array}{l}50 \\
50 \\
50\end{array}$ & & & 6.3 & \\
\hline & & 800 & 3.0 & 50 & & 3 & & 525 \\
\hline IPNS-II ${ }^{10}$ & ANL, Argonne & 400 & 2.2 & 30 & 196 & & 0.5 & 375 \\
\hline KEK/ETA ${ }^{11}$ & KEK, Japan & 1500 & 1.5 & 100 & & & 10 & \\
\hline KENS-II ${ }^{12}$ & JHF, Japan & 1000 & 1.0 & 50 & & $>0.2$ & 0.4 & \\
\hline LANSCE-II ${ }^{13}$ & LANL, Los Alamos & 800 & 0.8 & 120 & 145 & 0.57 & 1.25 & 420 \\
\hline PSNS $^{14}$ & BNL, Upton & 600 & $2 @ 3.6$ & 30 & 363 & 1.2 & 1.4 & 320 \\
\hline
\end{tabular}


The existing facilities generally have beam power $P_{B}$ much less than $1 \mathrm{MW}$ and beam energy $E_{0}$ less than $1 \mathrm{GeV}$. The proposed facilities with beam power $>1 \mathrm{MW}$ (except AUSTRON) are generally of energy $>1 \mathrm{GeV}$ except for the initial version of LANSCE-II which uses the existing LAMPF linac; extension of LANSCE-II to the $5 \mathrm{MW}$ power level contemplates beam energy up to $2 \mathrm{GeV}$. $^{13}$

\section{Neutron Yield}

The interest in higher proton energy stems from the experimental observations that the total neutron yield $Y_{n}$ of low energy $\left(E_{n}<15 \mathrm{MeV}\right)$ evaporation spectrum neutrons per incident proton increases approximately linearly with incident proton energy $E_{0}$. These data are shown in Fig. 1 where the Dubna data of Vassilkov, et al. ${ }^{15}$ up to $8.1 \mathrm{GeV}$ proton energy are shown together with the older ORNL-Chalk River data of Fraser, et al. ${ }^{16}$ for $\mathrm{E}_{\mathrm{o}} \leq 1.5 \mathrm{GeV}$. At higher energies the neutron yield clearly drops below linear, but at lower energy is reasonably represented by the linear expression given by Bauer ${ }^{17}$.

$$
Y_{n} \approx 0.1(A+20)\left[E_{0}(G e V)-.12\right] \text { neutrons/proton }
$$

where $\mathrm{A}$ is the atomic weight of the target nucleus. For present purposes we approximate Eq.(1) as $Y_{n} \propto E_{0}$. Then, from the expression for beam power

$$
P_{B}=N_{0} R_{p} E_{0}
$$

with $\mathrm{N}_{0}$ the number of protons per synchrotron pulse and the total number of protons in the ring assuming single turn extraction, and $R_{p}$ the repetition rate in pulses per second from the ring, it is clear that the beam power is proportional to the total neutron yield $\mathrm{N}_{\mathrm{T}}$ and is thus an appropriate parameter to characterize the merit of a neutron source. In practical units $E q .(2)$ is $P_{B}$ $(\mathrm{MW})=\bar{I}(\mathrm{~mA}) \mathrm{E}_{\mathrm{o}}(\mathrm{GeV})$.

From the user's point of view, however, the figure of merit is not necessarily the total yield since the additional neutrons result primarily from the hadron cascade as discussed in Sect. 3.2, BNL Design Report, ${ }^{39}$ and the neutron source region increases both transversely and longitudinally within the target volume with increasing $E_{o}$. The user benefits only from maximum flux at a given longitudinal position $Z$ along the target where the neutron beamline emerges approximately perpendicular to the proton beam direction. We therefore calculated (see Sect.3.2) the integrated $E_{n}$ $\leq 20 \mathrm{MeV}$ neutron flux at the target surface as a function of longitudinal position $Z$ along a solid $20-\mathrm{cm}$ diameter tungsten target for two limiting proton energies, 1 and $10 \mathrm{GeV}$ using the Monte Carlo code LAHET. ${ }^{18}$ These results, in Fig.2, and the numerical results on total yield from Sect. $3.2^{39}$ essentially confirm the approximately linear relation between neutron yield and proton energy noted above. Although the code has not been validated ${ }^{19}$ above $\mathrm{E}_{0} \approx 3.9 \mathrm{GeV}$ and must be used with caution for detailed comparisons at higher energy, we see that the $E_{0}=10-\mathrm{GeV}$ neutron source has a greater longitudinal extent, as expected, but a lower yield than a $1-\mathrm{GeV}$ source of ten times the proton intensity for small $Z(\leq 14-\mathrm{cm})$. With a segmented target we could therefore provide more segments 
with higher $\mathrm{E}_{\mathrm{o}}$ and thus more gaps for "flux trap" sources which appear to be the most desirable sources in terms of least high energy neutron contamination. In the present design of Sect.3.1 ${ }^{39}$ based on $\mathrm{E}_{\mathrm{o}}=3.6-\mathrm{GeV}$ a 3 -segment, 7.5-cm per segment target with two "flux trap" gaps is shown. At $10-\mathrm{GeV}$ perhaps four gaps could be provided with 6-cm segments if additional sources are desired by the user community. On the other hand, if the users are unable to utilize the additional neutrons beyond the peak of the cascade, then the extended tail from the high energy cascade is wasted and indeed contributes additional shielding cost.

\section{Proton Energy Range of Interest}

Eqs.(1) and (2) suggest that, if the highest attainable beam power $P_{B}$ and thus most intense neutron yield $N_{T}$ is desired, then we should increase $E_{o}$ indefinitely, subject to the constraint that $E_{0} \alpha$ cost. However $E_{o}$ is limited by a technical constraint imposed by the maximum tolerable pulse duration $\Delta t$, since the ring circumference $C$ is approximately proportional to $E_{o}$ (actually proton momentum $\mathbf{P}_{\mathrm{o}}$ ) and the pulse duration for single turn extraction is proportional to $\mathrm{C}$. Thus, for a conservatively designed FODO structure ring of the type proposed in the BNL Design Report, ${ }^{39}$ $C=363.2-\mathrm{m}$ gives a pulse length $\Delta t=1.24-\mu \mathrm{sec}$ at $P_{0}=4.44022 \mathrm{GeV} / \mathrm{c}$. We can then scale $C=\beta \mathrm{c}$ $\Delta t$ using the maximum tolerable beam pulse duration such as that suggested in the European design study $^{20} \Delta t \leq 3-\mu \mathrm{sec}$ and adopted for the European Spallation Source (ESS). Scaling from our present design the maximum circumference would be $C_{m}=896.1-\mathrm{m}$ and maximum proton momentum $\left(P_{a}\right)_{m}=10.955 \mathrm{GeV} / \mathrm{c}$ and kinetic energy $\left(E_{o}\right)_{m}=10.06 \mathrm{GeV}$. It should be noted here, however, that Bauer ${ }^{17}$ suggests a shorter pulse duration with $\Delta t \leq 1-\mu \mathrm{sec}$ most desirable and $\Delta t=2-3 \mu \mathrm{sec}$ acceptable if the option exists to shorten the pulse. For higher ring energy we would therefore have to contemplate single bunch extraction to serve the most stringent needs $(\Delta t \leq 0.5-\mu s e c)$ of the low rep rate $(10 \mathrm{~Hz})$ target for cold neutron beams. It should also be noted that it is possible to design a more compact ring in the energy region $\mathrm{E}_{0}<10 \mathrm{GeV}$ with use of higher peak magnetic field $\mathrm{B}$ than used in the present design. Several examples are given in Table III.

Table III. Several Rapid Cycling Synchrotrons with E $<10 \mathrm{GeV}$

\begin{tabular}{|c|c|c|c|c|c|c|c|}
\hline Ring & $\begin{array}{l}\mathrm{E}_{\mathrm{inj}} \\
(\mathrm{MeV})\end{array}$ & $\begin{array}{l}\mathrm{E}_{\mathrm{o}} \\
(\mathrm{GeV})\end{array}$ & $\mathrm{C}(\mathrm{m})$ & $\begin{array}{l}\Delta t \\
(\mu s e c)\end{array}$ & $\begin{array}{l}B_{m} \\
(k G)\end{array}$ & $\begin{array}{l}\mathbf{R}_{\mathbf{p}} \\
\text { (pps) }\end{array}$ & $\begin{array}{l}\dot{B}_{m} \\
(\mathrm{~T} / \mathrm{sec})\end{array}$ \\
\hline EHF-B & 1200 & 9.0 & 480 & 1.61 & 12.0 & $25^{*}$ & 50.63 \\
\hline ISIS $^{2}$ & 70 & 0.8 & 163.4 & 0.65 & 7.0 & 50 & 78.1 \\
\hline SSC-LEB ${ }^{23}$ & 600 & 7.12 & 249.6 & 0.84 & 12.4 & 10 & 33.02 \\
\hline $\operatorname{CEA}\left(e^{-}\right)^{24}$ & 20 & $\begin{array}{l}6.0\left(\mathrm{e}^{-}\right) \\
5.13(\mathrm{p})\end{array}$ & 226 & 0.76 & $7.6^{* *}$ & 60 & 143.26 \\
\hline BNL-SNS $^{39}$ & 600 & 3.6 & 363.2 & 1.24 & 6.9 & 30 & 47.12 \\
\hline
\end{tabular}

* dual frequency magnet excitation. $R_{p}($ accel $)=16.67 \mathrm{~Hz}$

** combined function bending magnet 
It is clear that other RCS designs have tolerated higher magnetic field and, for ISIS and the high energy electron machines such as the CEA, Daresbury, DESY-I and Yerevan, higher maximum rate of change of field $\dot{B}_{m}=(d B / d t)_{m}=\omega B_{0}$ with $B(t)=\bar{B}+B_{0} \sin (\omega t)$. Mills $s^{2 s}$ has noted that the Univ. Illinois betatron tolerated $\dot{B}_{m}=377 \mathrm{~T} / \mathrm{sec}$ at $R_{p}=60 \mathrm{~Hz}$. Thus, the pulse duration constraint $\Delta t$ $\leq 3-\mu \mathrm{sec}$ does not provide a hard upper bound on the proton energy. We have opted for a conservative design for $B_{m^{\prime}}, R_{p^{\prime}}$, and thus $\dot{B}_{m}$ to minimize eddy current fields and induced voltage $L$ $(\mathrm{di} / \mathrm{dt})$ across the magnets.

For the lower bound on the proton energy $E_{o}$ the dominant consideration is the energy loss per unit length in the vacuum window of the target and the target material itself. Bethe ${ }^{26}$ gives this expression for a projectile of charge ze as

$$
\mathrm{dE} / \mathrm{dx}=-\left(4 \pi N \mathrm{~N}^{4} \mathrm{Zz}^{2} / \mathrm{mv}\right)\left\{\ln \left(2 m v^{2} / \mathrm{I}\right)-\ln \left(1-\beta^{2}\right)-\beta^{2}\right\}
$$

where $\mathrm{N}$ and $\mathrm{Z}$ are the atom density and atomic number of the target, $\mathrm{m}$ is the electron rest mass and $I$ is the average ionization energy loss $I=k Z$ and is taken from Barkas and Berger ${ }^{27}$ for minimum ionizing protons. In practical units with target thickness increment $d \tau=\rho d x, E q .(3)$ is, for protons with $I$ in ev

$$
-\mathrm{dE} / \mathrm{d} \tau=3.0707510^{-4} \mathrm{Z} / \mathrm{A} \beta^{2}\left\{\ln \left(1.02199810^{6} \beta^{2} \gamma^{2} / \mathrm{I}\right)-\beta^{2}\right\} \mathrm{MeV} / \mathrm{g} / \mathrm{cm}^{2}
$$

We show $|d E / d \tau|$ for $C, A l, C u$ and $\mathrm{Pb}$ in Fig.3. It is clear that minimum energy loss is not attained for typical window materials such as $\mathrm{A}$ or typical heavy element targets like $\mathrm{Pb}$ until $\mathrm{E}_{\mathrm{O}} \geqslant 1.5 \mathrm{GeV}$. However, $|\mathrm{dE} / \mathrm{d} \tau|$ does not increase rapidly until $\mathrm{E}_{\mathrm{O}} \leqslant 500 \mathrm{MeV}$. Heidenreich and Bauer ${ }^{28}$ report that at the SINQ energy of $590 \mathrm{MeV}$ a stainless steel window can be designed to provide adequate safety margins up to $100 \mu \mathrm{A} / \mathrm{cm}^{2}$; from Fig. 3 it appears that one could do about $20 \%$ better for minimum ionizing protons. Bauer ${ }^{28}$ has also noted that in a comparison of peak power density depcsited in a 10-cm dia., $60-\mathrm{cm}$ long $\mathrm{Pb}$ target, the value for a $5 \mathrm{MW}$ beam with $\mathrm{E}_{0}=3 \mathrm{GeV}$ is a factor of $t$ wo less than for an $E_{0}=1 \mathrm{GeV}$ beam, 3.75 compared to $7.70 \mathrm{~kW} / \mathrm{cm}^{3}$. Atchison ${ }^{30}$ has made similar conclusions in comparing an $\mathrm{E}_{\mathrm{o}}=570 \mathrm{MeV}$ to $3.49 \mathrm{GeV}$ source. Thus, it is clear from the point of view of energy deposition that we want $E_{0} \geq 1 \mathrm{GeV}$ and the range of interest for protons is then approximately

$$
1 \leq \mathrm{E}_{\mathrm{o}} \leqslant 10 \mathrm{GeV}
$$

\section{Beam Current Considerations}

In the present study we are not attempting to maximize the beam power of Eq.(2); rather, we are designing for a fixed power of $P_{B}=5 \mathrm{MW}$. Thus, the right hand side of Eq.(2) is constrained-higher proton energy means smaller beam current $\bar{I}=\mathrm{e} \mathrm{N}_{0} \mathbf{R}_{\mathrm{p}}$. The beam current is limited by properties of the ring, the exit window and target, as well as beam loading effects in the Linac discussed in the BNL Design Report ${ }^{39}$ Sect. 4.2 and indeed ultimately by the $\mathrm{H}^{-}$ion source itself. 
Within the range of energies we are considering, the Linac, ring and target would all benefit from lower current. For the ring there are two major beam dynamics limitations on $\mathrm{N}_{0}$--space charge tune spread and collective instabilities. Both are dependent on $\mathrm{N}_{\mathrm{o}}$. We have considered the tune spread problem in Sect. 4.3.3, BNL Design Report, ${ }^{39}$ for a Gaussian space charge density $n(r)=n_{0} \exp \left(-\alpha^{2} r^{2}\right)$ with $\alpha^{2}=1 / 2 \sigma^{2}$ and obtain the approximate result for tune spread

$$
\Delta v(r)-r_{0} C N_{0}\left(1-e^{-\alpha^{2} r^{2}}\right) /\left\{4 \pi^{2} \beta^{2} \gamma^{3} B\left(1-e^{-\alpha^{2} r_{r}^{2}}\right) r^{2} v_{0}\right\}
$$

with $r_{0}=$ proton classical radius $\mathrm{e}^{2} / \mathrm{m}_{p} \mathrm{c}^{2}, \mathrm{C}=$ ring circumference, $r_{\mathrm{m}}$ the maximum extent of the machine acceptance ellipse and $B=$ bunching factor-fraction of circumference occupied by beam for the uniform longitudinal charge density distribution assumed in 4.3.3. ${ }^{39}$ The tune spread function is shown in Fig. 4 for our present acceptance of $A_{c}=\pi r_{m}^{2} / \bar{\beta}=320 \pi m m-m r$ (also called the admittance by Courant and Snyder $^{31}$ and Bruck $^{32}$ ). With a realistic bunching factor $B=0.25$ we can accommodate the $\mathrm{N}_{0}=1.4510^{14}$ particles per pulse required in the ring with a Gaussian RMS width $\sigma=31.93-\mathrm{mm}$ at a $\beta=\bar{\beta}$ point where $r_{m}=52.72-\mathrm{mm}$. If we substitute $C=2 \pi R$ and $\nu_{0}-R / \bar{\beta}$ in Eq. (6) and then take the limit $\sigma \rightarrow \infty$ we obtain the tune shift for a uniform space charge distribution, which yields the maximum value of $N_{0}$ for a ring of the above-stated acceptance and $B$ at injection energy $E_{0}=600$ $\mathrm{MeV}$ as

$$
\left(N_{o}\right)_{m}=2\left(\beta^{2} \gamma^{3}\right)_{\text {inj }} B A_{c}(\Delta v)_{u} / r_{o}=2.2710^{14} \text { protons }
$$

We therefore have some margin of safety in the assumed intensity value of the present design although a uniform charge distribution, as noted in Sect. 4.3.3, BNL Design Report ${ }^{39}$ is an idealization which would be difficult to attain with any reasonable injection bump.

It is of course possible to increase the number of protons $\mathrm{N}_{0}$ which can be stored in a ring by increasing the aperture and thus acceptance $A_{c}$ of Eq.(7). An increase in $N_{0}$ would then make possible a decrease in required proton energy $E_{0}$ to maintain a constant value for the right side of Eq.(2). This possibility requires both cost optimization and technical factors in that the growth rate of collestive instabilities, as discussed below, are proportional to $\left(\mathrm{N}_{0}\right)^{1 / 2}$. Another method to increase $N_{0}$ is to increase the Linac injection energy, i.e. the term $\left(\beta^{2} \gamma^{3}\right)_{\text {inj }}$ of Eqs. (6) and (7). This quantity is a rapidly increasing function of injection energy as seen in Fig. 5. Even the slope $d\left(\beta^{2} \gamma^{3}\right) / d E_{X}$ is increasing rapidly in this $600 \mathrm{MeV}$ energy region. An increase in $\mathrm{E}_{\mathrm{K}}$ from 600 to $900 \mathrm{MeV}$ increases $\beta^{2} \gamma^{3}$ and thus $N_{0}$ by a factor of 2 and could, for example, allow us to attain $P_{B}=5 \mathrm{MW}$ with one 3.6 $\mathrm{GeV}$ ring rather than the two presently proposed. The number of rings does not appear explicitly in Eq.(2); rather, it allows us to effectively increase the repetition rate $R_{p}$ of beam pulses on target without physically increasing the cycling rate of the magnet excitation. Again both cost and technical factors are involved. Is it more cost effective to increase the Linac energy to $900 \mathrm{MeV}$ rather than adding an additional 3.6 GeV RCS ring? Will the resultant increase in $\mathrm{N}_{0}$ by a factor of 2 give an unacceptable growth rate of collective instabilities? If not, could we increase the Linac energy to $1300 \mathrm{MeV}$ and attain an additional factor of 2 increase in $\mathrm{N}_{0}$ ? 
There is a myriad of collective instabilities which have been observed in circular accelerators and analyzed in terms of the interaction of wake fields generated by image currents in the vacuum chamber walls by the circulating beam, or fields induced in resonant structures by the beam. These are discussed in Sect. 4.3.7, BNL Design Report ${ }^{39}$ in terms of effective impedances which determine the magnitude of the fields generated by the beam which excites the instability. A more explicit formulation of the affect of the beam current on growth rate of instabilities appears in the earlier work on the subject, in particular the analysis of longitudinal and transverse instability in an unbunched beam resulting from wake fields in a resistive chamber wall by Neil and Sessler ${ }^{33}$ and Laslett, Neil and Sessler ${ }^{34}$ Transverse instability in bunched beams were subsequently analyzed by Courant and Sessler. ${ }^{35}$ These resistive wall instabilities are characterized by growth rates

$$
1 / \tau \alpha\left(N_{o} \rho\right)^{1 / 2}
$$

where $\rho$ is the resistivity of the wall material. Numerous other effects such as "head-tail" and "negative-mass" instability have been identified. The growth rate of the negative-mass instability ${ }^{36}$ is also proportional to $\mathrm{N}_{0}^{1 / 2}$. Other loss mechanisms such as intrabeam scattering - the Touschek Effect $^{37}$ - is characterized by a loss rate $1 / \tau \alpha \mathrm{N}_{0}$. In general these collective instabilities and loss mechanisms can be suppressed or entirely defeated by either passive or active counter-measures. The Head-tail instability can be defeated by additional sextupole magnets in the ring lattice and our lattice allows adequate space should sextupoles be required. Introduction of a momentum spread in the beam will defeat the negative mass instability. Active feedback has been used to suppress the transverse and longitudinal coupled bunch instabilities. In general the suppression of instabilities and beam intensity-dependent losses involve added cost and complexity. It should however be pointed out that the present application does not require the small final emittance which one must attain, for example, in an RCS injector for a colliding beam ring. We can tolerate some beam blow-up (but at the cost of more difficulty in extraction) because the final beam spot on the production target is intentionally increased after extraction--in our case to $5-\mathrm{cm} \mathrm{X}$ 20-cm--to reduce the energy density deposited in the exit window and target. Furthermore, the magnitude of the blow-up from both single particle and collective instabilities is dependent on the time duration of the acceleration cycle, which can be decreased by increasing the repetition rate $\mathbf{R}_{\mathbf{p}}$.

\section{Summary and Conclusions}

The present solution consists of two $3.6-\mathrm{GeV}$ rings with a $600-\mathrm{MeV}$ Linac injector, a compromise between conflicting factors of cost and technical concern. We believe that the design is a conservative one. We could increase the beam energy and/or the repetition rate and thereby decrease the requirement for the number of protons $\mathrm{N}_{0}$ in the ring which in the present design is an extrapolation of about a factor of 7 from existing ring intensities. However, the specified ring acceptance appears quite adequate to contain the required $1.4510^{14}$ protons/ring and the resulting loss in the target window and target are reasonable. Our beam power and current are indeed modest in terms of window and target integrity compared to the $200 \mathrm{MW}, 200 \mathrm{~mA} 1-\mathrm{GeV}$ design for the APT ${ }^{38}$ The two-ring approach also offers several practical advantages--the project is stageable in 
the sense that only one ring may be required initially to achieve $P_{B}=2.5 \mathrm{MW}$ power on the target with subsequent expansion to $5 \mathrm{MW}$ with addition of the second ring. Two rings also provide additional reliability in the sense that the user program need not be internupted by failure of one ring.

\section{Acknowledgments}

I thank A. van Steenbergen, A. Ruggiero, G. Bauer, M. Todosow and H. Ludewig for useful ideas and discussions.

\section{References}

1. A.V. Rauchas, Plenary talk \#3, IPNS Performance, Feb. 16, 1993, Workshop on Accelerators for Future Spallation Neutron Sources, Santa Fe, NM, Feb.15-21, 1993, sponsored by Los Alamos National Laboratory, A. Thiessen, chair.

2. C. Planner, ibid. ref. 1, Plenary talk \#4, Performance of ISIS, Feb. 16, 1993.

3. I. Yamane, Proc. Int. Collab. on Advanced Neutron Sources, ICANS-XII, Abingdon, U.K., May 24-28, 1993, paper C6.1, Vol.2, Rutherford Appleton Laboratory report RAL 94-025(1994).

4. Yu. Ya. Stavissky, Neutron Facilities of Moscow Meson and Kaon Factory, Proc. Int. Collab. on Advanced Neutron Sources ICANS-XI, Tsukuba, Japan, Oct.22-26, 1990, KEK report 90-25(March, 1991), p.87.

5. R. Macek, ibid. ref.1, Plenary talk \#7, PSR Performance, Feb.16, 1993.

6. G. Bauer, ibid. ref.4, SINQ-Status Report Oct.1990, p.41.

7. Yu. Ya. Stavissky and Yu. V. Senichev, ibid. ref .3, Advanced Neutron Source for Physical Research, Vol.II, p.36.

8. H. Schonauer, ibid. ref.1, Plenary talk \#9, Feb.16, 1993 and ref. 3. See also M. Regler, Proc. Int. Science Council (ISC) meeting, Vienna, Austria (Oct.29, 1993).

9. G. H. Rees, ibid. ref.1, Plenary talk \#8, Preliminary Design of 5-MW European Source, Feb. 16, 1993.

10. Y. Cho, ibid. ref.1, Plenary talk \#10, IPNS Upgrade Overview, Feb.16, 1993. See also B. S. Brown, ibid. ref.3, paper P1.3.

11. N. Watanabe, ibid. ref. 3, An Intense Pulsed Spallation Neutron Source Using a High-Power Proton Linac for Nuclear Transmutation, Vol.II, p.21. 
12. M. Kihara, ibid. ref. 4, Progress on the Accelerator R\&D for the Japanese Hadron Project, p. 140.

13. R. Pynn, ibid. ref. 3, paper P1.2. See also A. Jason, ibid. ref.1, Plenary talk \#11, Feb.16, 1993, The Los Alamos Reference Design.

14. A.G. Ruggiero and A. van Steenbergen, BNL report 49246(1993). See also L. Blumberg, ibid. ref. 3, Vol.2, paper A-20 and BNL report 49246(1993).

15. R.G. Vassil'kov, V.I. Yurevich and V.G. Khlopin, Proc.Int.Collab. on Advanced Neutron Sources ICANS-XI, Tsukuba, Japan, Oct.22-26, 1990, KEK report 90-25 (March, 1991)340.

16. J.S. Fraser, R.E. Green, J.W. Hilborn, J.C.D. Milton, W.A. Gibson, E.E. Gross and A. Zucker, Phys. Can. 21(2) 1966.

17. G. Bauer, ibid., ref.1, Plenary talk \#2, The Need for a Spallation Source, Feb.16, 1993.

18. R.E. Prael and H. Lichtenstein, Users Guide to LCS: The LAHET Code System, Los Alamos report LA-UR-89-3014 (Sept. 1989).

19. G. Russell and J. Carpenter, private communication, 1993.

20. K. Bongardt, et al., New European Accelerator-Based Spallation Neutron Source, report EPNS/AW1/M1/91, Simonskall, Germany, Sept. 9-11, 1991.

21. N. Watanabe, et al., Int.Workshop on Tech. of Targets and Moderators for Medium to High Power Spallation Neutron Sources, Paul Scherrer Inst., Villigen, Switz. Feb.10-14, 1992. See also G. Rees, ibid. ref.1.

22. J.F. Crawford, et al., Proposal for a European Hadron Facility, report EHF-87-18 (May, 1987).

23. Superconducting Super Collider Conceptual Design, SSC Central Design Group, J.D. Jackson, ed., SSC-SR-2020 (March, 1986).

24. The Cambridge Electron Accelerator: A Comprehensive Account, CEA report CEAL-1000, W.A. Shurcliff, ed. (March, 1964).

25. F. Mills, private communication, Feb. 1993.

26. H.A. Bethe, Z.Physik 76,293 (1938). See also H.A. Bethe and J. Ashkin in Exptl.Nucl.Phys., Vol.1, E. Segre, ed.(1952), Eqs.3 \& 4, p. 168. 
27. G. Barkas and M.J. Berger, Tables of Energy Losses and Ranges of Heavy Charged Particles, NASA-SP-3013 (1964). See also Review of Particle Properties, Phys. Lett.170B (10 April 1986) 48.

28. G. Heidenreich and G.S. Bauer, ibid., ref .21, Appendix C. See also G. Heidenreich, Preliminary Thermal and Stress Analysis of the SINQ Window, ICANS-XI, ibid. ref.15, p.536.

29. G.S. Bauer, invited paper, Symposium on Frontier Applications of Accelerators, BNL, Sept.28,1993, Z. Parsa, ed. Reference to T.A. Broome, private communication (Feb.1992).

30. F. Atchison, On the Choice of Proton Energy for a D.C. Spallation Neutron Source, Appendix D in ref.21.

31. E.D. Courant and H.S. Snyder, Ann.Phys. 3 (1958) 1, Eq. 3.23.

32. H. Bruck, Circular Particle Accelerators, Inst. Nat. des Sciences et Techniques Nucleaire, Saclay, France (1966). Translation: Los Alamos report LA-TR-72-10 Rev (1972), Eq. 8.17.

33. V.K. Neil and A.M. Sessler, Rev. Sci. Instr. 36 (1965) 429.

34. L.J. Laslett, V.K. Neil and A.M. Sessler, Rev. Sci. Instr. 36 (1965) 436.

35. E.D. Courant and A.M. Sessler, Rev. Sci. Instr.37 (1966) 1579.

36. H. Bruck, ibid. ref. 32, Eq.(29.30), p.318.

37. H. Bruck, ibid. ref. 32, Eq.(30.17), p.324.

38. Accelerator Production of Tritium (APT) Project, report DOE/S-0074 (Feb.1990). See also S. Drell, et al., JASON report, MITRE CORP., McLean, VA JSR-92-310(Jan.1992).

39. Brookhaven National Laboratory 5 MW Pulsed Spallation Neutron Source - Preconceptual Design Study, BNL Interdepartmental SNS Study Group, BNL report (in preparation, 1994), edited by $A$. van Steenbergen. 


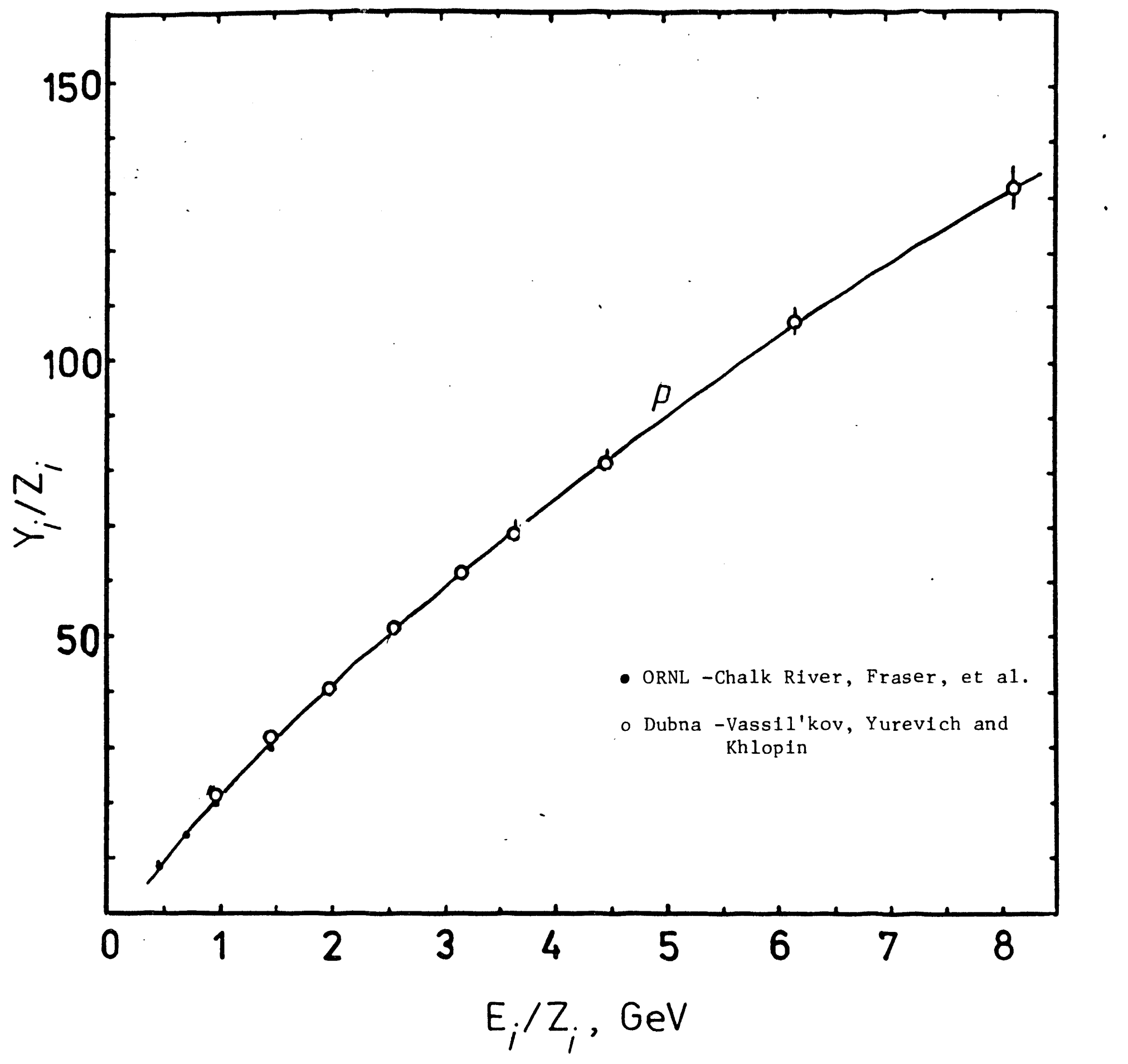

Fig. 1. Neutron yield per incident proton vs. proton energy in $20 \mathrm{~cm} \mathrm{dia.x}$ $60 \mathrm{~cm}$ long lead target. 


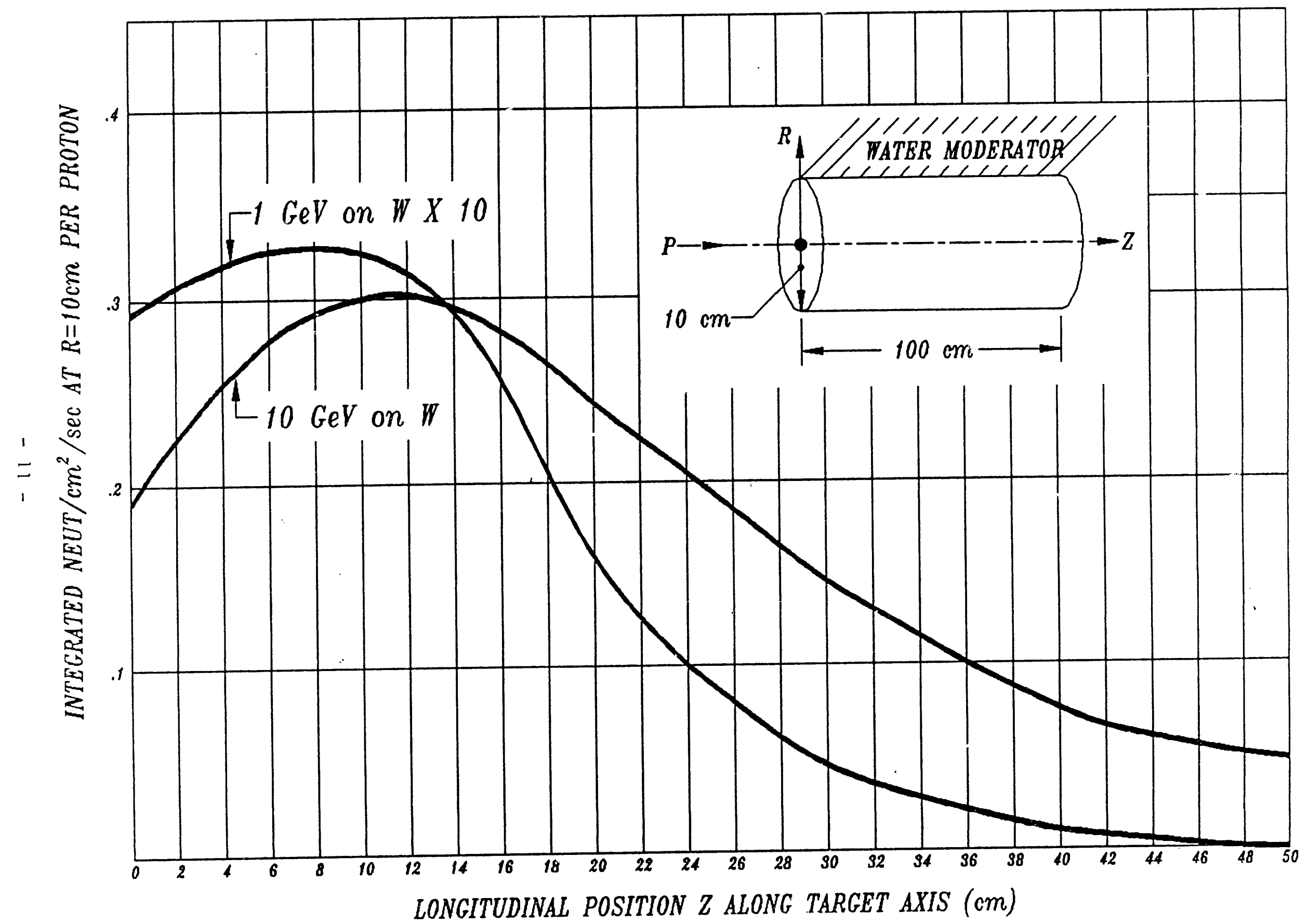

Fig. 2. Calculated neutron flux vs. longitudinal position along surface of $20 \mathrm{~cm}$ diameter Tungsten cylinder for $1-\mathrm{GeV}$ and $10-\mathrm{GeV}$ incident protons using Monte-Carlo code LAHET. (M. Todosow and H. Ludewig, BNL, 1993). 


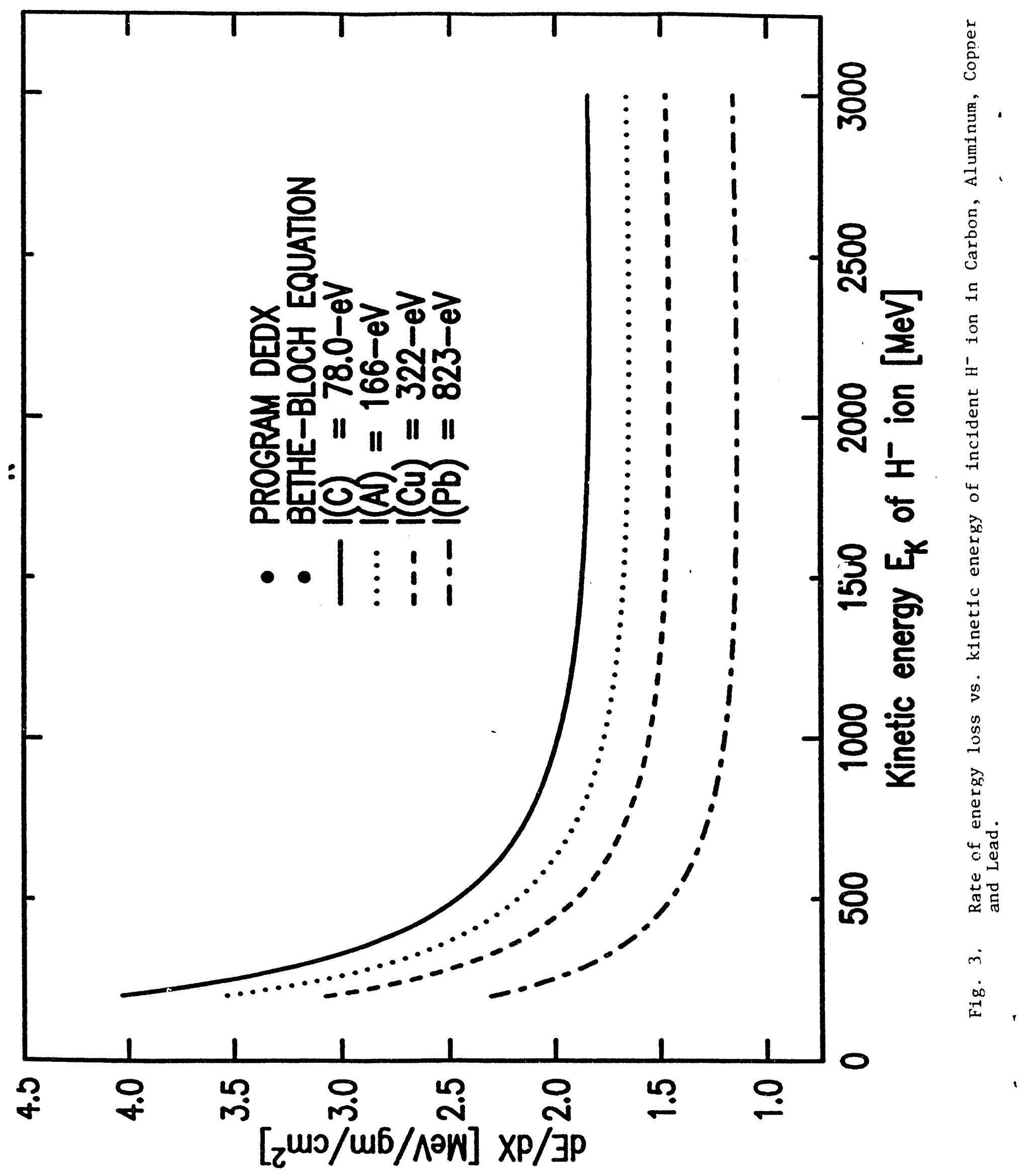




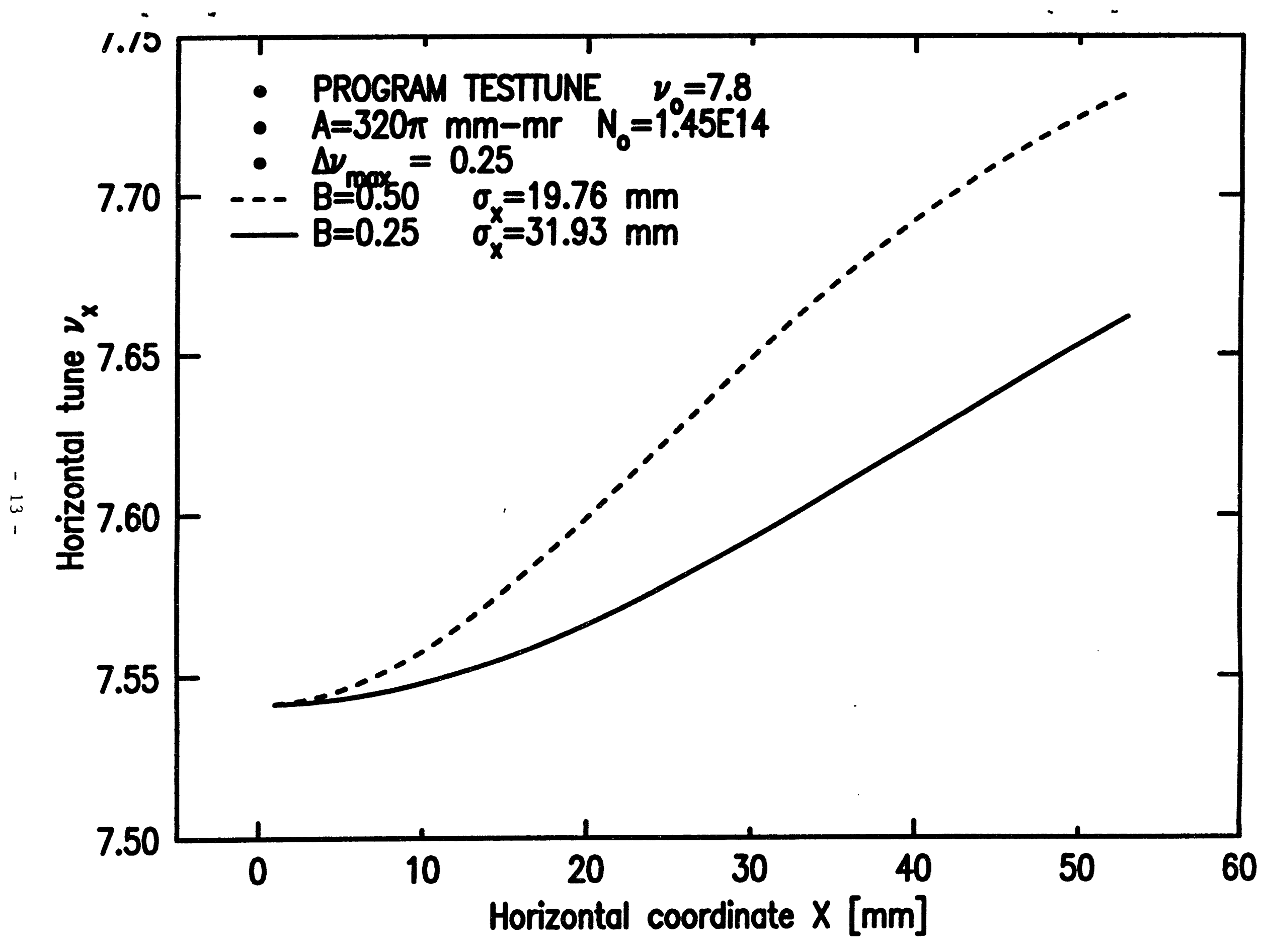

8
$\mathbf{9}$
$\mathbf{0}$
$\overline{8}$
$\overline{\mathbf{z}}$

Fig. 4. Tune shift vs. proton amplitude $\mathrm{x}$ for Gaussian space charge density. 


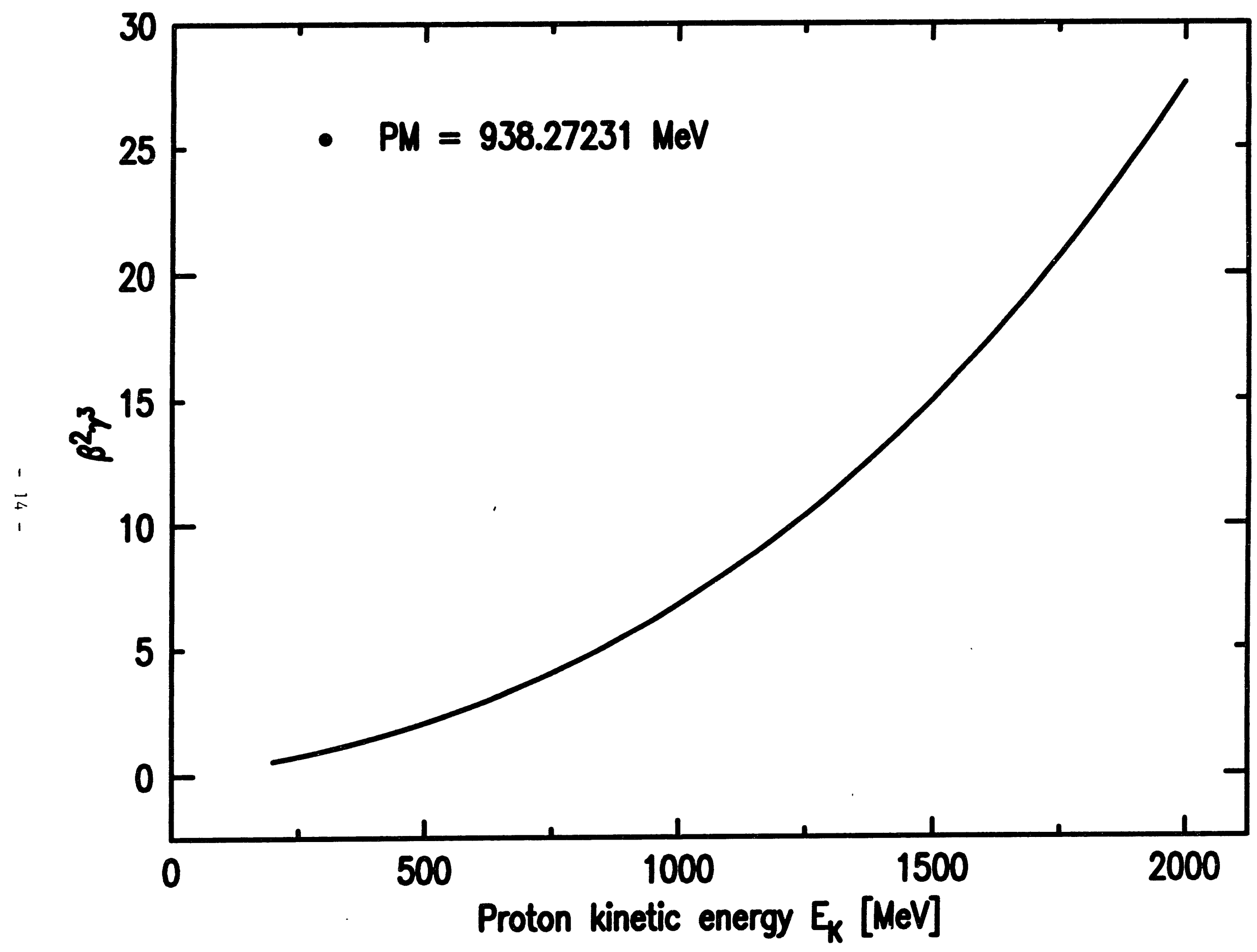

Fig. 5. $\beta^{2} \gamma^{3}$ vs. proton kinetic energy $E_{k}$. 

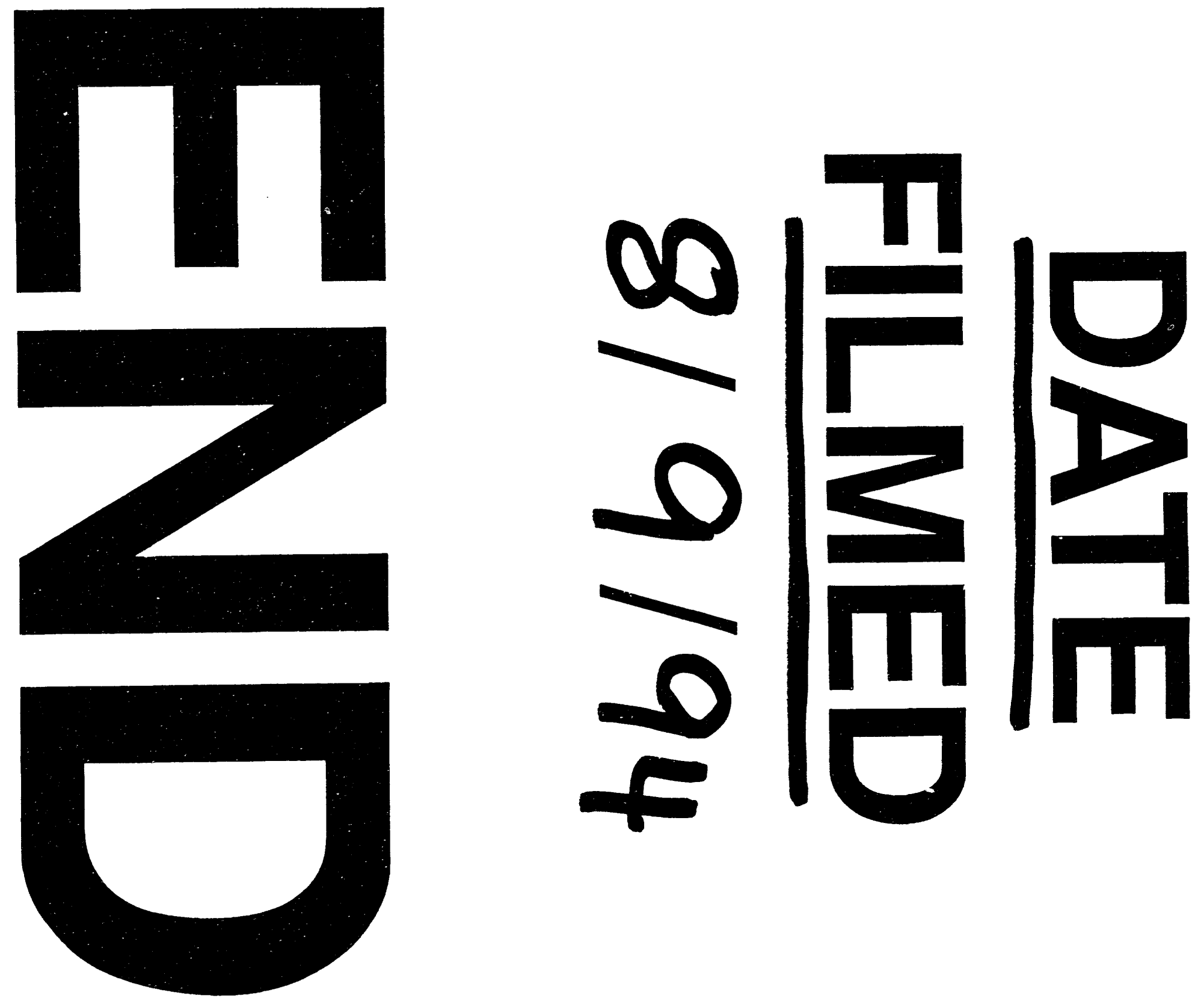
